\title{
Penilaian Kondisi Jalan dengan Metode Pci (Pavement Condition Index)
}

\author{
Fakhrul Rozi Yamali ${ }^{1}$, Elvira Handayani ${ }^{2}$, Eben Ezer Sirait ${ }^{3}$ \\ ${ }^{1,2}$ Dosen Fakultas Teknik Sipil Universitas Batanghari Jambi \\ ${ }^{3}$ Mahasiswa Teknik Sipil Universitas Batanghari Jambi \\ Email : fakhrul_65@yahoo.co.id
}

\begin{abstract}
Abstrak. Perkerasan jalan merupakan komponen pokok di bidang transportasi, Kondisi perkerasan mempengaruhi kenyamanan, keamanan dan keselamatan pengguna jalan. Dalam metode PCI, tingkat keparahan kerusakan perkerasan merupakan fungsi dari 3 faktor utama, yaitu: tipe kerusakan, tingkat keparahan kerusakan, jumlah atau kerapatan kerusakan. PCI ini merupakan indeks numerik yang nilainya berkisar diantara 0 sampai 100. Berdasarkan hasil penelitian didapatkan Jenis dan nilai rata-rata kerusakan pada ruas Jl.Jambi-lintas Muara Bulian Kelurahan Muara Pijoan sampai Jl.Jambi-lintas Muara Bulian KM 27 desa Lopak Aur dengan panjang $4 \mathrm{KM}$ dan lebar $6 \mathrm{M}$ antara lain : Retak Buaya (1.473\%), Retak Kotak-Kotak (0.078\%), Retak Pinggir Jalan (0.083\%), Pinggir Jalan Turun Vertiakal (0.038\%), Retak Memanjang/Melintang (0.065\%), Tambalan (3.018\%), Lubang $(0.200 \%)$, Alur $(0.049 \%)$, Sungkur $(0.076 \%)$, Pelepasan Butir (2.878\%), Amblas (0.037\%) dengan nilai PCI rata-rata yaitu $48.90 \%$.
\end{abstract}

Kata Kunci: Kerusakan Jalan, Metode PCI

\section{PENDAHULUAN}

Jalan mempunyai peranan yang sangat penting bagi kehidupan manusia. Untuk masa sekarang dan masa yang akan datang, pada era industrialisasi, perdagangan serta angkutan umum, angkutan barang dan jasa, harus didukung oleh infrastruktur yang memadai, salah satunya adalah dengan adanya prasarana darat yaitu jalan raya. Karena jalan didalam Provinsi Jambi khususnya pada jalan arteri di Kabupaten Muaro Jambi sampai Batanghari salah satunya adalah ruas jalan Jambi lintas Muara Bulian dilewati kendaraan berat diantaranya mobil truk lebih dari 659 unit dan mobil bus 267 unit perhari yang diperoleh dari data LHR pada tanggal 29-Agusutus-2019, maka penurunan tingkat pelayanan dapat berupa kerusakan pada permukaan jalan. Dari hasil penelitian didapat kerusakan sebanyak 11 jenis kerusakan dari 19 jenis kerusakan sesuai dengan standar Dirjen Bina Marga No.03/MN/B/1983 dengan panjang 4 km dan lebar jalan $6 \mathrm{~m}$.

Adapun tujuan dari penelitian ini adalah sebagai berikut: 1) 1.Menganalisis jenis kerusakan yang terjadi pada ruas Jalan Jambi-lintas Muara Bulian Kelurahan Muara Pijoan sampai Jl.Jambi-lintas Muara Bulian Km 27 desa Lopak Aur; 2) Menganalisis Performance permukaan jalan mengunakan metode PCI (pavement Condition Index) oleh U.S. Army Corp of Engineer (Shahin et al., 1976-1984); 3) Menentukan jenis penanganan kerusakan ruas jalan berdasarkan Metode Standar Dirjen Bina Marga 1995 No. 002/T/Bt/1995.

Pavement Condition Index (PCI) adalah penilaian kondisi kerusakan perkerasan yang dikembangkan oleh U.S. Army Corp of Engineer (Shanin et al., 1976-1984), dinyatakan dalam Indeks Kondisi Perkerasan (Pavement Condition IndeksI, PCI). Penggunaan PCI untuk perkerasan bandara, jalan, dan tempat parkir telah dipakai secara luas di Amerika. Dapertemen-dapertemen yang menggunakan prosedur PCI ini misalnya:

1. FAA (Federal Aviation Administrasion, 1982).

2. Dapertemen Pertahanan Amerika (U.S. Air Force, 1981; U.S. Army, 1982).

3. Asosiasi Pekerjaan Umum Amerika (American Public Work Association, 1984).

Metode Pavement Condition Index(PCI) adalah salah satu sistem penilaian kondisi perkerasan jalan berdasarkan jenis, tingkat kerusakan yang terjadi dan dapat digunakan sebagai acuan dalam usaha pemeliharaan. Dalam metoda PCI tingkat keparahan kerusakan perkerasan merupakan fungsi dari 3 faktor utama, yaitu :

1. Tipe kerusakan lapisan permukaan jalan.

2. Tingkat keparahan kerusakan lapisan permukaan jalan.

3. Jumlah atau kerapatan kerusakan lapisan permukaan jalan.

Kondisi perkerasan seperti tersebut diatas digunakan untuk semua jenis kerusakan. Kerusakan jalan dapat dibagi menjadi 19 macam kerusakan dan dalam setiap macam kerusakan dibagi lagi menjadi 3 tingkat kerusakan, yaitu :

Low $(\mathrm{L}) \quad=$ Rusak ringan

Medium (M) = Rusak sedang

$\operatorname{High}(\mathrm{H}) \quad=$ Rusak parah

1. Retak Kulit Buaya

2. Retak Kotak-kotak

3. Amblas

4. Retak Pinggir Jalan 
5. Pinggir Jalan Turun Vertikal

6. Retak Memanjang/Melintang

7. Tambalan

8. Alur

9. Sungkur

10.Pelepasan Butiran

11.Lubang

12.Patah Slip

13.Retak Sambungan

14.Pengausan Agregat

15. Keriting

16.Kegemukan

17.Perpotongan Rel

18.Cekungan

19.Mengembang Jembul

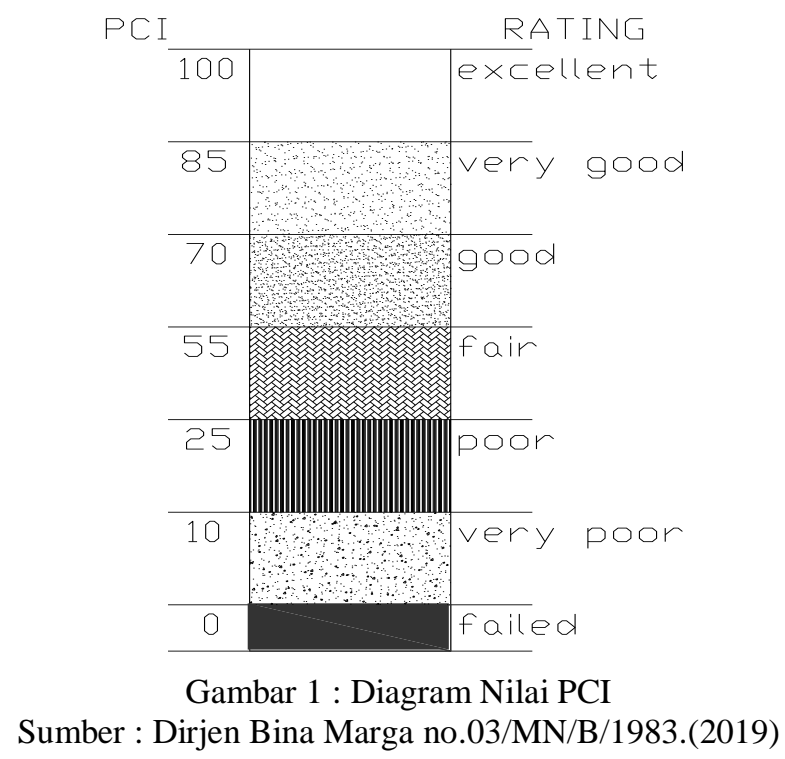

METODE

Metode yang digunakan dalam survei ini adalah metode dengan cara deskriptif analisis berdasarkan metode Pavement Condotion Index (PCI). Diskriptif berarti survei yang memusatkan pada masalah-masalah yang ada pada saat sekarang, keadaan kerusakan perkerasan jalan yang diteliti, sedangkan analisis berarti data yang dikumpulkan dan disusun, kemudian dianalisis dengan mengunakan prinsip-prinsip analisis Metode Pavement Condition Index (PCI). Shahin(1994)/Hardiytamo, H.C, (2007).

\section{HASIL}

Dari hasil pengamatan visual di lapangan diperoleh luas kerusakan, kedalaman ataupun lebar retak yang nantinya dipergunakan untuk menentukan kelas kerusakan jalan. Densitas kerusakan ini dipengaruhi oleh kuantitas tiap jenis kerusakan dan luas segmen jalan yang ditinjau. Penentuan deduct value dapat segera dihitung setelah kelas kerusakan dan densitas diperoleh. Total Deduct Value (TDV) dan Corrected Deduct Value (CDV) dapat dihitung segera setelah tahapan-tahapan di atas sudah diketahui nilainya. Tahap akhir dari analisis nilai kondisi perkerasan adalah menentukan nilai Pavement Condition Index (PCI), yang selanjutnya dapat digunakan untuk menentukan prioritas penanganan kerusakan. Langkah-langkah perhitungan dengan metode PCI adalah sebagai berikut:

1. Membuat Catatan Kondisi Dan Kerusakan Jalan

2. Memasukkan nilai-nilai luasan kerusakan

3. Menentukan nilai pengurang (deduct value)

a. Jumlahkan tipe kerusakan pada setiap tingkat keparahan kerusakan yang terlihat.

b. Menghitung densitas

Densitas $(\%)=($ Luas atau panjang Kerusakan/Luas Perkerasan $)$

c. Hitung Nilai-Pengurangan (Deduct Values) dari tabel grafik-grafik Nilai Pengurangan untuk Hitungan PCIjalan dengan Permukaan Perkerasan Asphal (Shahin 1994). 
d. Mencari nilai-pengurang terkoreksi maksimum $(C D V)$

Untuk mendapatkan nilai CDV dengan yaitu dengan cara memasukkan nilai TDV yang lebih ke grafik CDV dengan cara menarik garis vertikal pada nilai CDV sampai memotong garis q kemudian ditarik garis horizontal. Nilai q merupakan jumlah DV yang lebih dari 5

e. Menghitung PCI

Nilai PCI $=100-$ CDV

Dengan :

PCI = Nilai Kondisi Perkerasan (100)

$\mathrm{CDV} \quad=$ Corrected Deduct Value

Tabel 1. Hasil Perhitungan Corrected Deduct Value (CDV)

\begin{tabular}{|c|c|c|c|c|c|c|c|c|c|}
\hline STA & & & EDT & ALT & & & TOTAL & $\mathbf{q}$ & CDV \\
\hline $0+000$ S/D 0+100 & 8 & 3 & 26 & 79 & & & 116 & 3 & 79 \\
\hline $0+100$ S $/ D 0+200$ & 71 & 47 & 11 & 5 & $\mathbf{1}$ & 8 & 143 & 4 & 81 \\
\hline $0+200$ S $/ D 0+300$ & 14 & 40 & 14 & & & & 68 & 3 & 42 \\
\hline $0+300 \leq / D 0+400$ & 35 & 5 & 16 & 4 & & & 60 & 2 & 44 \\
\hline $0+400$ S $/ D 0+500$ & - & - & - & - & - & - & - & - & - \\
\hline $0+500 \mathrm{~s} / \mathrm{D} 0+600$ & 6 & 4 & & & & & 10 & $\mathbf{1}$ & 10 \\
\hline $0+600$ S/D $0+700$ & 44 & 27 & & & & & 71 & 2 & 52 \\
\hline $0+700$ S/D $0+800$ & 31 & 27 & & & & & 58 & 2 & 43 \\
\hline $0+800$ S/D $0+900$ & 4 & 29 & 4 & 46 & & & 83 & 2 & 60 \\
\hline $0+900$ S/D $1+000$ & 34 & 20 & & & & & 54 & $\overline{2}$ & 39 \\
\hline $1+000 \mathrm{~S} / \mathrm{D} 1+100$ & 8 & 71 & 11 & $\mathbf{1}$ & & & 91 & 3 & 58 \\
\hline $1+100$ S $/ D \quad 1+200$ & 26 & 25 & 66 & & & & 117 & 3 & 79 \\
\hline $1+200$ S $/ D 1+300$ & 71 & 34 & 2 & 26 & & & 133 & 3 & 86 \\
\hline $1+300 \mathrm{~S} / \mathrm{D} 1+400$ & 44 & 24 & 17 & & & & 85 & 3 & 55 \\
\hline $1+400 \mathrm{~S} / \mathrm{D} 1+500$ & 25 & 13 & 4 & $\mathbf{1}$ & 24 & & 67 & 3 & 43 \\
\hline $1+500$ S/D $1+600$ & 31 & & & & & & 31 & $\mathbf{1}$ & 31 \\
\hline $1+600$ S/D $1+700$ & 46 & 27 & 13 & & & & 86 & 3 & 55 \\
\hline $1+700$ S/D $1+800$ & 25 & 16 & & & & & 41 & 2 & 31 \\
\hline $1+800 \mathrm{~S} / \mathrm{D} 1+900$ & 13 & 11 & & & & & 24 & $\overline{2}$ & 18 \\
\hline $1+900$ S/D $2+000$ & 34 & 10 & & & & & 44 & 2 & 33 \\
\hline $2+000$ S/D $2+100$ & 26 & 11 & & & & & 37 & 2 & 29 \\
\hline $2+100$ S/D $2+200$ & 34 & 4 & 8 & 16 & 7 & & 69 & 4 & 39 \\
\hline $2+200$ S/D $2+300$ & 29 & 12 & & & & & 41 & 2 & 31 \\
\hline $2+300$ S/D $2+400$ & 31 & 13 & 71 & 21 & & & 136 & 4 & 77 \\
\hline $2+400$ S/D $2+500$ & 14 & 87 & 49 & 10 & 11 & & 171 & 5 & 85 \\
\hline $2+500$ S/D $2+600$ & 68 & 16 & 16 & & & & 100 & 3 & 64 \\
\hline $2+600$ S/D $2+700$ & 68 & 35 & 16 & & & & 119 & 3 & 73 \\
\hline $2+700$ S/D $2+800$ & 37 & 12 & 71 & & & & 120 & 3 & 74 \\
\hline $2+800$ S/D $2+900$ & 41 & 16 & 91 & & & & 148 & 3 & 87 \\
\hline $2+900$ S/D $3+000$ & 13 & 46 & 8 & 3 & & & 70 & 3 & 45 \\
\hline $3+000$ S/D $3+100$ & 41 & 8 & 26 & & & & 75 & 3 & 48 \\
\hline $3+100$ S $/ D$ 3+200 & 41 & 13 & 16 & 47 & & & 117 & 4 & 61 \\
\hline $3+200$ S/D $3+300$ & 23 & 26 & 87 & & & & 133 & 3 & 86 \\
\hline $3+300$ S/D $3+400$ & 47 & & & & & & 47 & $\mathbf{1}$ & 47 \\
\hline $3+400$ S/D $3+500$ & 39 & & & & & & 39 & $\mathbf{1}$ & 39 \\
\hline $3+500$ S/D $3+600$ & 42 & & & & & & 42 & $\mathbf{1}$ & 42 \\
\hline $3+600$ S/D $3+700$ & 38 & 66 & & & & & 104 & 2 & 72 \\
\hline $3+700$ S/D $3+800$ & 57 & 16 & & & & & 73 & 2 & 53 \\
\hline $3+800$ S/D $3+900$ & 17 & & & & & & 17 & $\mathbf{1}$ & 17 \\
\hline $3+900$ S/D $4+000$ & 3 & 31 & & & & & 34 & $\mathbf{1}$ & 34 \\
\hline
\end{tabular}

Sumber : Data Olahan (2019)

Tabel 2. Hasil Perhitungan Pavement Condition Indeks (PCI)

\begin{tabular}{|c|c|c|c|c|c|c|}
\hline No & & STA & $\begin{array}{l}\text { IUUAS } \\
\text { SERMMN (m²) }\end{array}$ & CDAX & PCI & LEVEL \\
\hline $\mathbf{1}$ & $\begin{array}{l}0+000 \\
0+100\end{array}$ & $5 / 20+100$ & 600 & 79 & 21 & $\begin{array}{c}\text { POOR } \\
\text { YERY POOR }\end{array}$ \\
\hline 3 & $0+200$ & S/D0+300 & 600 & 42 & 58 & GoOD \\
\hline 4 & $0+300$ & $5 / 20+400$ & 600 & 44 & 56 & GOOD \\
\hline 5 & $0+400$ & $S / 100+500$ & 600 & - & 100 & EXELTENT \\
\hline 6 & $0+500$ & $5 / 0+600$ & 600 & 10 & 90 & VERY GOOD \\
\hline 7 & $0+600$ & S/D $0+700$ & 600 & 52 & 48 & FAIR \\
\hline $\mathbf{8}$ & $0+700$ & $S / D 0+800$ & 600 & 43 & 57 & 6000 \\
\hline 9 & $0+800$ & $5 / 00+900$ & 600 & 60 & 40 & FATR \\
\hline 10 & $0+900$ & $5 / D 1+000$ & 600 & 39 & 61 & G00D \\
\hline 11 & $1+000$ & $5 / D 1+100$ & 600 & 58 & 42 & FATR \\
\hline 12 & $1+100$ & $5 / D 1+200$ & 600 & 79 & 21 & VERY POOOR \\
\hline 13 & $1+200$ & $5 / 1+300$ & 600 & 86 & 14 & VERY POOOR \\
\hline 14 & $1+300$ & $5 / D 1+400$ & 600 & 55 & 45 & FATR \\
\hline 15 & $1+400$ & $5 / 1+500$ & 600 & 43 & 57 & GoOD \\
\hline 16 & $1+500$ & $5 / 1+600$ & 600 & 31 & 69 & G00D \\
\hline 17 & $1+600$ & $5 / 1+700$ & 600 & 55 & 45 & FAIR \\
\hline 18 & $1+700$ & $5 / 01+800$ & 600 & 31 & 69 & GoOD \\
\hline 19 & $1+800$ & $5 / 11+900$ & 600 & 18 & 82 & VERY GOOOD \\
\hline 20 & $1+900$ & $5 / 2+000$ & 600 & 33 & 67 & GoOD \\
\hline 21 & $2+000$ & $5 / 02+100$ & 600 & 29 & 71 & VERY GOOOD \\
\hline 22 & $2+100$ & $5 / 2+200$ & 600 & 39 & 61 & Goob \\
\hline 23 & $2+200$ & $\sin 2+300$ & 600 & 31 & 69 & GoOD \\
\hline 24 & $2+300$ & $\sin 2+400$ & 600 & 77 & 23 & VERY POOR \\
\hline 25 & $2+400$ & $5 / 02+500$ & 600 & 85 & 15 & VERY POOR \\
\hline 26 & $2+500$ & $5 / 2+600$ & 600 & 64 & 34 & FATR \\
\hline 27 & $2+600$ & $5 / 02+700$ & 600 & 73 & 27 & POOR \\
\hline 28 & $2+700$ & $5 / 02+800$ & 600 & 74 & 26 & POOR \\
\hline 29 & $2+800$ & $5 / 2+900$ & 600 & 87 & 13 & VERT POOOR \\
\hline 30 & $2+900$ & $5 / D 3+000$ & 600 & 45 & 55 & GoOD \\
\hline 31 & $3+000$ & $5 / 3+100$ & 600 & 48 & 52 & FATR \\
\hline 32 & $3+100$ & $5 / 3+200$ & 600 & 61 & 39 & POOR \\
\hline 33 & $3+200$ & $\sin 3+300$ & 600 & 86 & 14 & VERT POOOR \\
\hline 34 & $3+300$ & $5 / 3+400$ & 600 & 47 & 53 & FATR \\
\hline 35 & $3+400$ & $5 / 03+500$ & 600 & 39 & 61 & Go00 \\
\hline 36 & $3+500$ & $5 / 03+600$ & 600 & 42 & 58 & G000 \\
\hline 37 & $3+600$ & $\sin 3+700$ & 600 & 72 & 28 & POOR \\
\hline 38 & $3+700$ & $5 / 3+800$ & 600 & 53 & 47 & FATR \\
\hline 39 & $3+800$ & $5 / 23+900$ & 600 & 17 & 83 & VERT GOOOD \\
\hline 40 & $3+900$ & $5 / D 4+000$ & 600 & 34 & 66 & GooD \\
\hline \multicolumn{3}{|c|}{$?$} & 24000 & 2042 & $\begin{array}{r}1956 \\
48,90\end{array}$ & FATR \\
\hline
\end{tabular}

Sumber : Data Olahan (2019) 
Tabel 3. Presentase Kerusakan

\begin{tabular}{ccc}
\hline No & Jenis Kerusakan & Presentase Kerusakan $(\%)$ \\
\hline 1 & Retak Kulit Buaya & 0,073 \\
2 & Retak Kotak-kotak & 0,037 \\
3 & Amblas & 0,083 \\
4 & Retak Pinggir Jalan & 0,038 \\
5 & Pinggir Jalan Turun Vertikal & 0,065 \\
6 & Retak Memanjang/Melintang & 3,018 \\
7 & Tambalan & 0,049 \\
8 & Alur & 0,076 \\
9 & Sungkur & 2,878 \\
10 & Pelepasan Butiran & 0,200 \\
11 & Lubang & - \\
12 & Patah Slip & - \\
13 & Pengausan Agregat & - \\
14 & Keriting & - \\
15 & Kegemukan & - \\
16 & Perpotongan Rel & - \\
17 & Cekungan & - \\
18 & Retak Sambungan & - \\
\hline
\end{tabular}

Sumber : Data Olahan (2019)

\section{SIMPULAN}

Berdasarkan hasil analisa data dan pembahasan yang telah dilakukan, maka dapat disimpulkan beberapa hal, yaitu sebagai berikut:

1. Pada ruas Jl.Jambi-lintas Muara Bulian Kelurahan Muara Pijoan sampai Jl.Jambi-lintas Muara Bulian KM 27 desa Lopak Aur, sepanjang $4000 \mathrm{~m}(4 \mathrm{~km})$ dan lebar perkerasan jalan $6 \mathrm{~m}$ terdapat 11 jenis kerusakan dengan tingkat kerusakan yang berbeda-beda

2. Nilai PCI terendah terdapat pada STA $0+100-0+200$, STA $1+100-1+200$, STA $1+200-1+300$, STA $2+300-$ $2+400$, STA $2+400-2+500$, STA $2+800-2+900$, STA 3+200 - 3+300 dengan klasifikasi sangat jelek (Very Poor).

3. Nilai indeks kondisi perkerasan (PCI) rata-rata pada ruas pada ruas Jl.Jambi-lintas Muara Bulian Kelurahan Muara Pijoan sampai Jl.Jambi-lintas Muara Bulian KM 27 desa Lopak Aur adalah 48,90\% termasuk dalam kategori (Fair)/sedang.

4. Metode Perbaikan kerusakan fungsional digunakan metode perbaikan P2, P3, dan P5 sesuai dengan Metode Standar Dirjen Bina Marga 1995 No 002/T/Bt/1995

5. Metode PCI (Pavement Condition Indeks) hanya memberikan informasi kondisi perkerasan pada saat dilakukannya survey, tapi tidak dapat memberikan gambaran prediksi dimasa yang akan datang.

\section{DAFTAR PUSATAKA}

Agus.,Surwandi.,2008."Evaluasi Tingkat Kerusakan Jalan Dengan Metode Pavement Condition Index, (Studi Kasus : Jalan Lingkar Selatan, Yogyakarta ).

Departemen Pekerjaan Umum Direktorat Jenderal Bina Marga. (1995) Tata Cara Penyusunan Program Pemeliharaan Jalan Kota, Nomor : 002/T/Bt/1995

Hardiyatmo H.C., 2007, Pemeliharaan Jalan Raya, Gajah Mada University Press, 'Yogyakarta.

Departemen Pekerjaan Umum., 1983, Tata Cara Perencanaan Geometrik Jalan Kota No. 03/MN/B/1983, Direktorat Jenderal Bina Marga, Jakarta, Indonesia.

Shahin,M.Y., 1994, Pavement Management for Airport, Road, and Parking Lots, Chapman \& Hall, New York.

Sukirman, S., 1999, Perkerasan Lentur Jalan Raya, Badan Penerbit Nova, Bandung.

Kementerian Pekerjaan Umum Dikretorat Jenderal Bina Marga, 2013. Manual Desain Perkerasan Jalan No. 02/M/BM/2013, Jakarta. 